\title{
Role of protein repair enzymes in oxidative stress survival and virulence of Salmonella
}

\author{
Arijit Shome ${ }^{1 *} \mathbb{D}$, Ratanti Sarkhel', Shekhar Apoorva', Sonu Sukumaran Nair ${ }^{2}$, Tapan Kumar Singh Chauhan', \\ Sanjeev Kumar Bhure ${ }^{1}$ and Manish Mahawar ${ }^{1}$
}

\begin{abstract}
Purpose: Proteins are the principal biomolecules in bacteria that are affected by the oxidants produced by the phagocytic cells. Most of the protein damage is irreparable though few unfolded proteins and covalently modified amino acids can be repaired by chaperones and repair enzymes respectively. This study reviews the three protein repair enzymes, protein L-isoaspartyl O-methyl transferase (PIMT), peptidyl proline cis-trans isomerase (PPlase), and methionine sulfoxide reductase (MSR).
\end{abstract}

Methods: Published articles regarding protein repair enzymes were collected from Google Scholar and PubMed. The information obtained from the research articles was analyzed and categorized into general information about the enzyme, mechanism of action, and role played by the enzymes in bacteria. Special emphasis was given to the importance of these enzymes in Salmonella Typhimurium.

Results: Protein repair is the direct and energetically preferred way of replenishing the cellular protein pool without translational synthesis. Under the oxidative stress mounted by the host during the infection, protein repair becomes very crucial for the survival of the bacterial pathogens. Only a few covalent modifications of amino acids are reversible by the protein repair enzymes, and they are highly specific in activity. Deletion mutants of these enzymes in different bacteria revealed their importance in the virulence and oxidative stress survival.

Conclusion: PIMT repairs isoaspartate residues, PPiase catalyzes the conversion of cis-trans forms of proline residues, while MSR repairs oxidized methionine (Met) residues in the proteins. These repair enzymes maintain the activities of the target protein(s), thus aid in bacterial survival and virulence. The interventions which can interfere with this mechanism could be used for the development of novel therapeutics.

Keywords: Oxidative stress, Protein damage, Protein repair, Salmonella, Poultry

\section{Introduction}

Phagocytes constitute a very important part of host innate immunity. After sensing microbial ligands, phagocytes produce various reactive oxygen species (ROS), reactive nitrogen species (RNS), antimicrobial peptides, chemokines, and cytokines with an overall goal to contain or kill the invaders and help other immune cells to generate adaptive immunity. Upon activation, NADPH

\footnotetext{
* Correspondence: arijitshome25@gmail.com

'Division of Animal Biochemistry, Indian Council of Agricultural ResearchIndian Veterinary Research Institute (ICAR-IVRI), Izatnagar, Bareilly 243 122, India

Full list of author information is available at the end of the article
}

oxidase (NOX) gets assembled on the phagosomal membrane and pumps the electrons from NADPH to oxygen by generating superoxide anions $\left(\mathrm{O}_{2}^{-}\right) \cdot \mathrm{O}_{2}^{-}$is then metabolized into a variety of other toxic ROS, like hydrogen peroxide $\left(\mathrm{H}_{2} \mathrm{O}_{2}\right)$ and hydroxyl radicals $\left({ }^{\circ} \mathrm{OH}\right)$ (Miller and Britigan, 1997). Further, myeloperoxidase catalyzes the production of highly toxic reactive chlorine species (RCS), hypochlorous acid ( $\mathrm{HOCl}$ ) from $\mathrm{H}_{2} \mathrm{O}_{2}$, and chloride ions (Fig. 1). It has been demonstrated that phagocyte-generated NADPH oxidase plays a very vital role in controlling bacterial pathogens, including Salmonella enterica serovar Typhimurium infection. Simultaneously, inducible nitric oxide synthase (iNOS) gets

(c) The Author(s). 2020 Open Access This article is licensed under a Creative Commons Attribution 4.0 International License, which permits use, sharing, adaptation, distribution and reproduction in any medium or format, as long as you give appropriate credit to the original author(s) and the source, provide a link to the Creative Commons licence, and indicate if changes were made. The images or other third party material in this article are included in the article's Creative Commons licence, unless indicated otherwise in a credit line to the material. If material is not included in the article's Creative Commons licence and your intended use is not permitted by statutory regulation or exceeds the permitted use, you will need to obtain permission directly from the copyright holder. To view a copy of this licence, visit http://creativecommons.org/licenses/by/4.0/. 


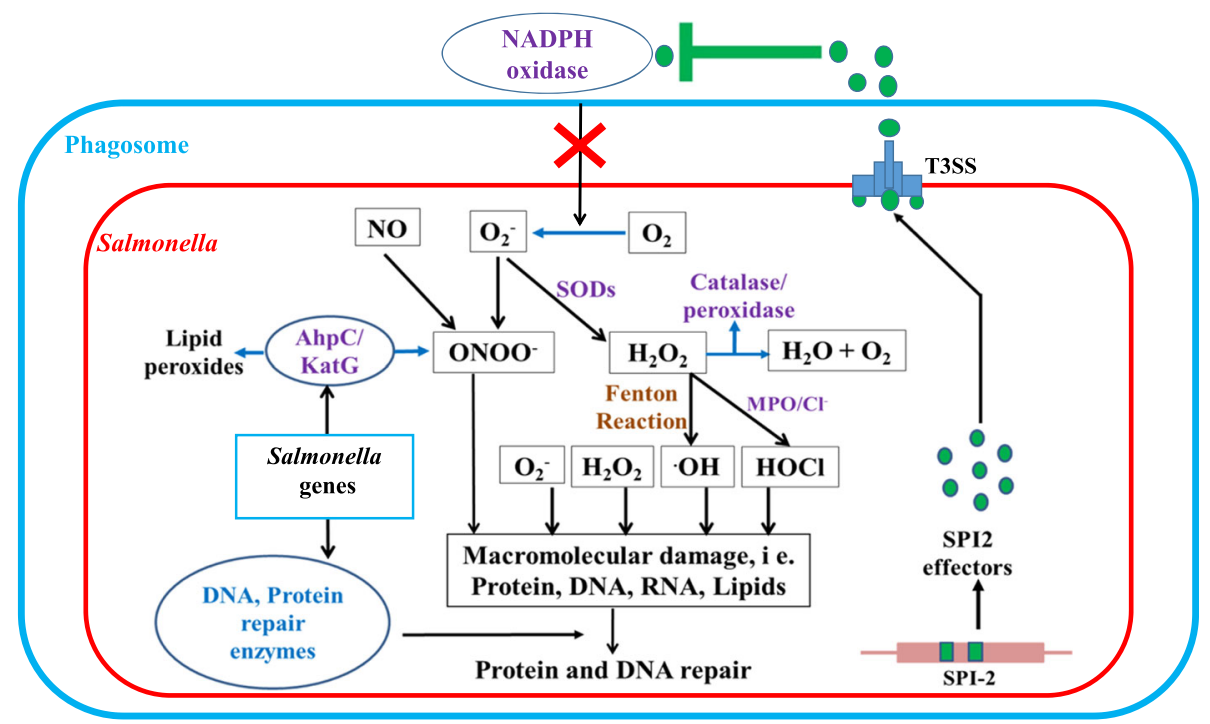

Fig. 1 Antioxidant defenses of Salmonella: Phagocytes produce an array of ROS/RNS which exert microbicidal effect by damaging macromolecules. Salmonella handles ROS/RNS in three ways. First, by injecting SPI2 effectors into the host phagosome, Salmonella inhibits NADP $\mathrm{H}$ oxidase assembly thus interfere with the $\mathrm{O}_{2}^{-}$production. Second, various primary antioxidants of Salmonella directly inactivate ROS/RNS. Third, DNA and protein repair enzymes restore the functions of damaged DNA, and proteins

activated and catalyzes the oxidation of one of the guanidine nitrogens of $\mathrm{L}$-arginine to generate nitric oxide (NO). NO gets autooxidized to produce other reactive nitrogen species like $\mathrm{NO}_{2}{ }^{\circ}, \mathrm{N}_{2} \mathrm{O}_{3}$, and S-nitrosothiols which are more reactive and have enhanced cytotoxic abilities (Fang, 1997). Further, the combination of NO and $\mathrm{O}_{2}^{-}$forms peroxynitrite $\left(\mathrm{ONOO}^{-}\right)$, which is one of the most potent RNS. Phagosomal oxidase and iNOS knockout mice were found to be more susceptible to Salmonella infection (Felmy et al. 2013). Almost all macromolecules, including DNA, RNA, lipids, and proteins, are susceptible to ROS- and RNS-mediated damage (Fig. 1).

The genus Salmonella includes two species, Salmonella enterica and Salmonella bongori. Salmonella enterica is further divided into six subspecies I (enterica), II (salamae), IIIa (arizonae), IIIb (diarizonae), IV (houtenae), and VI (indica) (Le Minor L \& Popoff MY 1987; Popoff et al. 1998). These subspecies are further classified into various serovars. Based on host preference and adaptability, the Salmonella enterica subspecies enterica are categorized into two serovars, i.e., typhoidal (includes $S$. Typhi and S. Paratyphi) and non-typhoidal (NTS, includes $S$. Enteritidis and $S$. Typhimurium) (Hohmann, 2001; Parry et al. 2002; Gal-Mor et al. 2012). Typhoidal Salmonellae are the causative agents of "enteric fever," which is characterized by prolonged fever, fatigue, and severe gastroenteritis. Most pathogenic species of Salmonella which are the leading cause of foodborne gastroenteritis across the globe causing illness in humans belong to the species Salmonella enterica. Poultry serves as reservoir of Salmonellae and acts as major source of human infection (Bailey et al. 2002, Velge et al. 2005). Poultry meat and eggs have been implicated in the large outbreaks of foodborne Salmonellosis (Leach et al. 1999; Humphery, 2000). In 2015, WHO in its 10 year report of global burden of foodborne diseases identified Salmonellosis as the most common foodborne illness and estimated approximately 230,000 deaths in the USA alone due to non-typhoidal Salmonella enterica (NTS) (WHO, 2015). In the same year, the eggs contaminated with Salmonella spp. were associated with the highest number of foodborne outbreaks reported and were among the top five foodborne pathogen in terms of overall illness (EFSA and ECDC, 2016). Normally, NTS causes self-limiting, mild to moderate gastroenteritis in healthy adults. However, young, old, and immuno-compromised individuals are at a higher risk, wherein NTS causes severe gastroenteritis to invasive, extra-intestinal disease culminating in bacteremia and infections in multiple organs (Mandal and Brennand, 1988; Lê-Bury and Niedergang, 2018).

Salmonella can replicate in a variety of host cells. One important feature of this bacterium is its ability to infect and replicate inside the phagocytic cells. Recent studies suggest that Salmonella can survive and replicate in neutrophils, which are considered a dead-end for most bacterial pathogens (Geddes et al. 2007). Virulence of $S$. Typhimurium has been correlated with its survival in the phagocytic cells, whereas mutants that are unable to survive inside the macrophages are considered avirulent (Fields et al. 1986).

Salmonella handles oxidants in three ways. First, it injects Salmonella pathogenicity island 2 (SPI2) effectors 
into the host cell that interfere with the assembly of phagosomal oxidase, thus modulating the production of $\mathrm{O}_{2}{ }^{-}$(Vázquez-Torres et al. 2000; Gallois et al. 2001) and consequently other ROS and RNS. Second, the primary antioxidants of Salmonella directly detoxify the oxidant species. Third, macromolecular (DNA and protein) repair enzymes mend damaged DNA and proteins and restore their functions without de novo synthesis.

Among primary antioxidants, Salmonella encodes four superoxide dismutases (SodA, SodB, SodCI, SodCII), three catalases (KatE, KatG, KatN), and three peroxiredoxins (AhpC, TsaA, Tpx). SODs neutralize $\mathrm{O}_{2}^{-}$; Kats scavenge $\mathrm{H}_{2} \mathrm{O}_{2}$; peroxiredoxins reduce organic hydroperoxides and $\mathrm{H}_{2} \mathrm{O}_{2}$ (Fang, 2011; Slauch, 2011; Aussel et al. 2011). AhpC and KatG degrade $\mathrm{ONOO}^{-}$(McLean et al. 2010; Henard and Vázquez-Torres, 2011) (Fig. 1). During the respiratory burst, the quantity of phagocyte-generated oxidants can be much higher than the scavenging capacity of primary antioxidants (SOD, catalases, peroxiredoxins, etc.) of Salmonella. Furthermore, microbial enzymes that can degrade host-generated toxic oxidants like ${ }^{\circ} \mathrm{OH}$ and $\mathrm{HOCl}$ which results in macromolecular damage are not known yet. Therefore, DNA and protein repair enzymes help Salmonella to cope with oxidative insult and ensure its propagation in the host.

Due to their abundance and reactivity, proteins are highly prone to oxidative damage. Two types of protein damage are known including covalent modifications to amino acids and changes in the secondary structure (Mahawar et al. 2011). Degradation of damaged proteins to amino acids followed by ribosomal synthesis is an obvious and well-studied way to replenish damaged proteins. On the other hand, protein repair is a rapid and energyefficient approach to reactivate damaged proteins without de novo synthesis (Brot et al. 1981; Zhang and Weissbach 2008). Under stress conditions, when limited resources are available to the cell, the repair of vital protein(s) becomes indispensable for cellular survival (either the cell repairs them or it dies). Chaperones can refold unfolded proteins. However, even though various covalent modifications have been described (Hawkins et al. 2003), only three types of repair enzymes are known: (1) protein L-isoaspartyl O-methyltransferase (PIMT), (2) peptidyl prolyl cis-trans isomerase (PPIase), and (3) methionine sulfoxide reductase (MSR) which repair damaged aspartate or asparagine (isoaspartate), isomerized proline, and oxidized methionine residues respectively ( $\mathrm{Li}$ and Clarke, 1992; Boschi-Muller et al. 2008; Ünal and Steinert, 2014).

\section{Protein L-isoaspartyl 0-methyl transferase}

Aspartyl (Asp)/asparaginyl (Asn) residues in proteins spontaneously get converted into iso-aspartate (iso-Asp) as a part of normal post-translational modification which decides the half-life of the protein (Güttler et al. 2013).
But under the condition of certain stresses, their rate of formation has been shown to accelerate. Iso-Asp formation leads to distortion of protein structure resulting in unfolding and aggregation of the proteins. Thus iso-Asp formation has been linked to compromised protein function (Kern et al. 2005; Shimizu et al. 2005; Dimitrijevic et al. 2014) which consequently affects cellular survival. Protein L-isoaspartyl O-methyl transferase (PIMT) (EC 2.1.1.77), a product of $p c m$ gene in bacteria, methylates the $\alpha$-carboxyl group on iso-Asp residues by using the methyl group of S-adenosyl-L-methionine (AdoMet), thus producing methyl esters. By repairing iso-Asp to Asp, PIMT restores the protein function(s) partially and thereby enhances cellular survival under stress conditions (Dimitrijevic et al. 2014).

\section{Mechanism of PIMT-mediated repair}

Asp/Asn residues in proteins, spontaneously or under stress, get converted into succinimide. The hydrolysis of succinimide yields isoAsp and Asp in a ratio of 3:1 (Vigneswara et al. 2006). The PIMT transfers methyl group from $\mathrm{S}$-adenosyl methionine to isoAsp residues resulting in the formation of iso-aspartyl methyl esters which are unstable and rapidly hydrolyzed to form succinimide (Fig. 2). With multiple cycles of such reactions, the aspartyl residues can be salvaged and thereafter proteins regain their functions (DeVry and Clarke, 1999; Dimitrijevic et al. 2014).

\section{Effect of $p \mathrm{~cm}$ gene deletion on the survival of various organisms}

The $p c m$ gene knockout strain of E. coli (Li and Clarke, 1992; Visick et al. 1998; Hicks et al. 2005) showed hypersensitivity to oxidative, temperature, and other stresses. On the other hand, the PIMT overexpressing E. coli cells showed enhanced tolerance to oxidative and temperature stresses (Kindrachuk et al. 2003;Verma et al. 2010). The enhanced survival capabilities of PIMT overexpressing cells under temperature stress were shown to be due to the methyltransferase independent activities of PIMT (Kindrachuk et al. 2003). The structure crystallographic study of PIMT in E. coli has revealed the presence of 2 highly conserved $\mathrm{Glu}^{81}$ (E81) and $\mathrm{Glu}^{104}$ (E104) in the binding site of PIMT for AdoMet (Kindrachuk et al. 2003). The same study undertook the in situ mutagenesis of glutamine residues to alanine in PIMT of E.coli cells (E81A and E104A mutants) to analyze the specific effects of PIMT on cellular survival. It was observed that upon exposure to temperature stress, overexpressed wild and inactive PIMT (E81A) led to increased but comparable survival rates, while the E104A inactive mutant showed the highest cellular survival. Since, E104A inactive mutant had no methyltransferase activity, the study postulated a different role of 


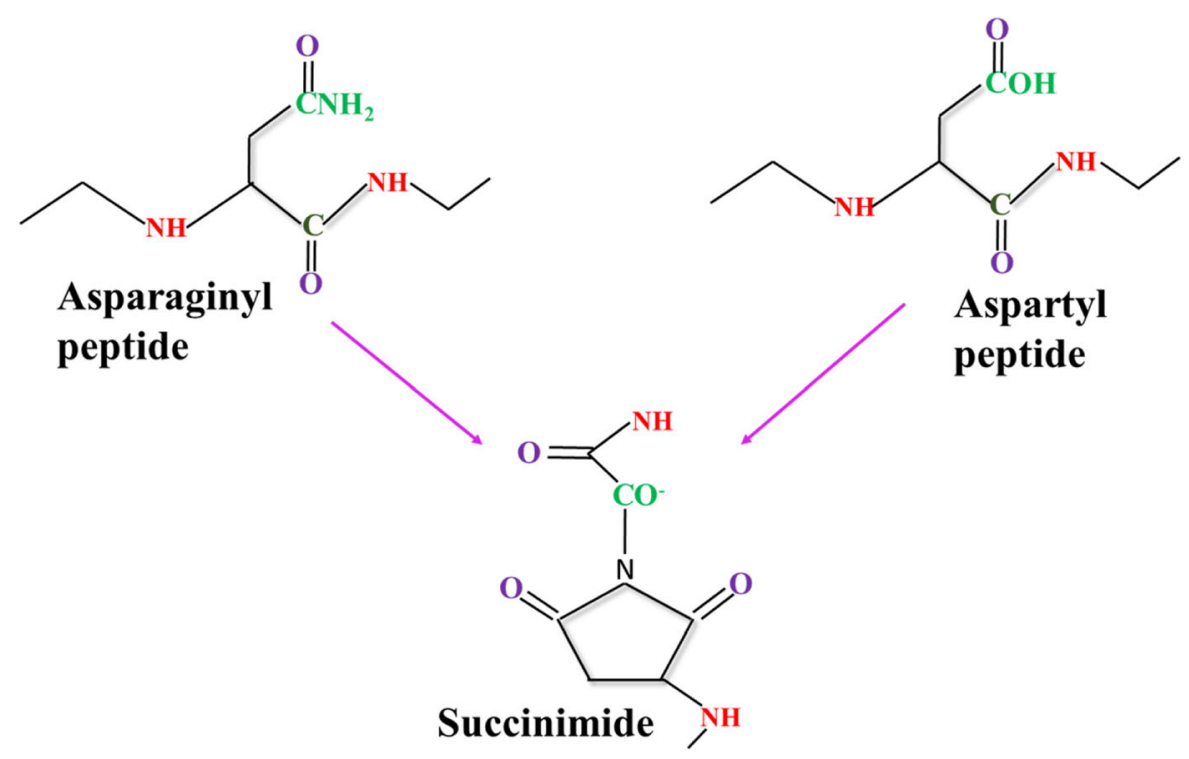

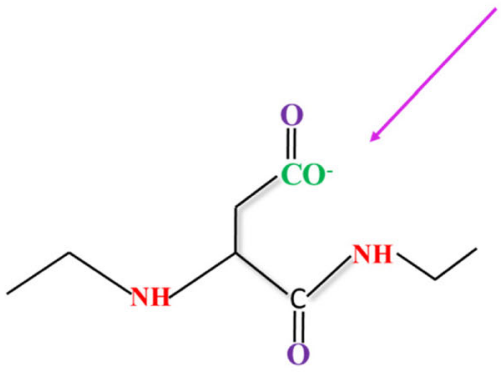

Aspartyl peptide

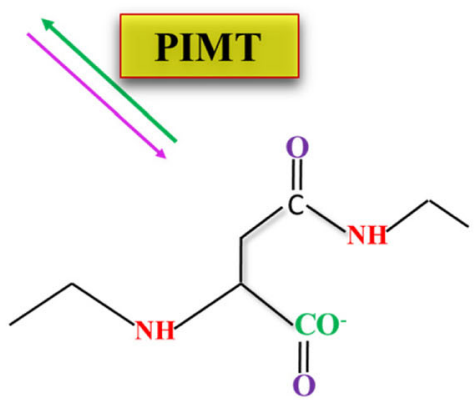

Isoaspartyl peptide

Fig. 2 Conversion of Asp to iso-Asp and their repair by PIMT: Under stress Asp or Asn residues in the proteins convert into succinimide. Succinimide spontaneously convert into normal Asp or abnormal iso-Asp residues in a ratio of 1:3. PIMT catalyzes conversion of iso-Asp residues into succinimide. Few cycles of PIMT-mediated repair converts all iso-Asp to Asp

PIMT in enhancing cellular survival other than its stereotypical role of enzymatic repair. Further, the western blot study revealed the overexpression of DnaK chaperone protein in E104A inactive mutant under temperature stress. Therefore, the study highlights the importance of a methyltransferase independent role of PIMT in increasing cellular survival through the induction of heat shock proteins. Thus, this study suggested methyl-transferase dependent as well as the independent role of PIMT in the survival of E. coli against temperature stress (Kindrachuk et al. 2003).

\section{PIMT in S. Typhimurium}

PIMT contributes to the resistance of $S$. Typhimurium against hydrogen peroxide, hypochlorous acid, and temperature stresses in vitro (Kumawat et al. 2016; Pesingi et al. 2017). The survival of $\Delta p c m$ mutant strain inside interferon- $\gamma$ (IFN- $\gamma$ ) stimulated macrophages was found to be 10-folds less as compared to the parent WT strain $(p<0.001)$, and it also showed attenuated virulence to mice (Kumawat et al. 2016). Further, the $\mathrm{pcm}$ gene is required for colonization in poultry cecum and dissemination to the spleen and liver (Pesingi et al. 2017). The expression of PIMT protein was about threefold higher following exposure of $S$. Typhimurium at $42^{\circ} \mathrm{C}$ (Pesingi et al. 2017). On the other hand, $\mathrm{HOCl}$ exposure induced PIMT by 1.5 -fold (Kumawat et al. 2016), suggesting a greater role of this protein under thermal than oxidative stress.

\section{Peptidyl proline cis-trans isomerase}

Among the various known post-translational modifications of proteins, the dynamics of polypeptide chains can also be affected by catalytic activity of foldases. PPIases are a type of foldases that catalyze the isomerization between the cis and trans forms of peptide bonds, by the $180^{\circ}$ rotation about the prolyl bond (Fig. 3) (Lin et al. 2019) and expedite the folding of nascent polypeptides 
as well as the refolding of unfolded and misfolded proteins (Compton, et al. 1992; Schmid et al. 1993). Due to steric hindrance exerted by side chains of amino acids, almost all peptide bonds exist as trans-conformers. However, in the case of proline, due to the formation of the pyrrolidine ring, the peptide bond can be present either in normal trans- or in cis-configuration. The presence of the abnormal proline-cis bond spontaneously affects folding, refolding, and protease-mediated degradation of the polypeptide chain and consequently influences protein function(s) (Brandts et al. 1975; Cook et al. 1979). PPIases are mostly found to be localized in the bacterial periplasm, inner membrane, and cytoplasm and are sometimes present in the supernatant (secreted) (Hayano et al. 1991; Kim et al. 2002; Söderberg and Cianciotto. 2008; Delpino et al. 2009). Localization in different compartments suggests a variety of differentially distributed targets for PPIases.

The PPIases can be grouped under one superfamily comprising three families of proteins, namely cyclophilins (Cyps)-PpiA, FK506-binding proteins (FKBPs) FkpA, SylD, and parvulins like SurA (Ünal and Steinert, 2014). PpiA is localized in the periplasm. FKBP-type peptidyl-prolyl cis-trans isomerase (FkpA), a product of the $f k p A$ gene, and cyclophilin PpiA catalyze the same isomerization reaction. Chaperone SurA encoded by the surA gene helps in the correct folding and assembly of outer membrane proteins. Structurally, SurA has an Nterminal region, two parvulin-like domains, and a Cterminal tail. The PPIase activity resides in one of the parvulin domain. The $\mathrm{N}$-terminal region and the $\mathrm{C}$ terminal tail are necessary and sufficient for the chaperone activity of SurA. This was demonstrated by a study in which a variant of SurA composed of only Nterminal region and the $\mathrm{C}$-terminal tail (lacking the parvulin domains) exhibited chaperone activity in spite of lacking the PPIase parvulin domain (Behrens et al. 2001).

\section{PPlase in bacterial virulence}

PPIases are shown to be induced during the accumulation of misfolded proteins, heat and cold stresses, (Kandror and Goldberg, 1997; Söderberg and Cianciotto, 2008; Fasseas et al. 2012) and infection processes (Port and Freitag, 2007). The role of PPIase in bacterial virulence is mostly explained by its ability to facilitate proper folding of secreted proteins, adhesins, and other virulence factors (Hermans et al. 2006; Purdy et al. 2007; Alonzo and Freitag, 2010; Behrens-Kneip, 2010; Forster et al. 2011). In Streptococcus suis, Listeria monocytogenes, and Clostridioides difficile, PPIases are required for resistance against several stresses including thermal, oxidative, and acid stresses, thereby contributing to virulence in mice (Bigot et al. 2006; Wu et al. 2011; Ünal et al. 2018). PPIase gene deletion strains of E. coli and Yersinia pseudotuberculosis showed defective adherence to and invasion of host cells (Justice et al. 2006; Obi and Francis, 2013) and virulence in mice (Hermans et al. 2006; Cron et al. 2009). A recent study demonstrated the role of Legionella pneumophila PPIase in the infection of both Acanthamoeba castellanii and human macrophages (Rasch et al. 2018).

\section{PPlase in Salmonella}

The $f k p A$ and surA genes are required for Salmonella survival during long-term carbon starvation and the cross-resistance of carbon-starved cells to acidic $\mathrm{pH}$, high temperature, and antimicrobials (Kenyon et al. 2010). Deletion mutant strains of $f k p A$ and surA genes were found to be defective in survival in epithelial cells and macrophages and showed attenuated virulence in mice (Horne et al. 1997; Sydenham et al. 2000; Humphreys et al. 2003). Cyclophilin A (CypA) is a eukaryotic protein belonging to the PPIase family. A recent study suggested the role of CypA in the membrane ruffling<smiles>[R]C(NC)C1[Te][Te][Ge]N1C(=O)C([R])([R])NC</smiles>

\section{Peptidyl - proline (cis-)}

Peptidyl - proline (trans-)

Fig. 3 Conversion of cis- and trans- forms of proline by PPlase 
and internalization of $S$. Typhimurium into HeLa cells (Dhanda et al. 2018).

\section{Methionine sulfoxide reductases}

The sulfur-containing amino acids (Met and Cys) are highly prone to oxidation (Hawkins et al. 2003). Upon oxidation, Met residues convert into methionine sulfoxides (Met-SO) and further oxidation leads to the formation of methionine sulfones. MSRs reductively repair Met-SO to Met; however, sulfone repair enzymes are not yet known (Fig. 4). MSR-mediated repair of Met-SO plays two important roles in the cell. First, the MSRmediated repair restores the functions of Met-rich oxidized proteins (Mahawar et al. 2011; Kuhns et al. 2013). Second, surface-exposed Met residues in proteins act as oxidant sinks. These surface-exposed Met residues get oxidized during the respiratory burst of host immune response and sop up excess oxidants, thus limiting damage to the cell until oxidized Met-SO gets repaired by MSRs (Abulimiti et al. 2003; Luo et al. 2009; Benoit and Maier, 2016; and Schmalstig et al. 2018).

\section{Mechanism of MSR-mediated repair}

Oxidation of sulfur in methionine forms either $S$ or $R$ epimers. According to localization, there are two types of MSRs, cytoplasmic and periplasmic (Boschi-Muller et al. 2008). MsrA and MsrB, which are present in cytoplasmic compartment repair $S$ and $R$ epimers of MetSO, respectively. A third MSR was later discovered in the cytoplasm and named as MsrC. It is specific for free Met-R-SO and had been first described in E. coli (Lin et al. 2007) and then in $S$. Typhimurium (Denkel et al. 2011). MsrA reduces both free and protein-bound Met$\mathrm{S}-\mathrm{SO}$ whereas, MsrB reduces mainly protein-bound Met-R-SO with limited action on free Met-R-SO. All these MSRs repair Met-SO in thioredoxin -thioredoxin reductase manner where NADPH serves as an electron donor for the reduction process. The catalytic mechanism of MSR is a three step process involving three cysteine residues. In the first step, a nucleophilic Cys residue (CysA) attacks a Met-SO substrate, which leads to the formation of a sulfenic acid (-SOH) group on CysA and the release of reduced Met. In the second step, a nucleophilic Cys residue (CysB) attacks CysA-SOH, which leads to the formation of an intramolecular disulfide intermediate and the release of a water molecule. In the third step, the intramolecular disulfide intermediate is reduced by a Trx protein, and a catalytically active MSR enzyme is regenerated (Ezraty et al. 2017).

Periplasmic MSR (MsrP) has been discovered very recently in Gram negative bacteria. This new methionine sulfoxide reductase system, named MsrPQ, involves two proteins encoded in the same operon. MsrP, which carries out the reductase activity, is a periplasmic, soluble protein with a molybdenum atom in its active site. It was previously named YedY until its MSR activity was discovered (Loschi et al. 2004). To be functional in vivo, MsrP has to be specifically associated with MsrQ, an integral B-type heme-containing membrane-spanning protein, previously named YedZ (Drew et al. 2002). For the reduction reaction, MsrP receives electrons from MsrQ which in turn acquires electrons from quinones (JuillanBinard et al. 2017).

\section{Role of MSRs in bacterial virulence}

The role of bacterial msr gene in combating various stresses within the host system has been well established. Further, its role in virulence also has been shown in many studies. An msrA gene deletion mutant of $\mathrm{Myco}$ plasma genitalium exhibited hypersusceptibility to $\mathrm{H}_{2} \mathrm{O}_{2}$

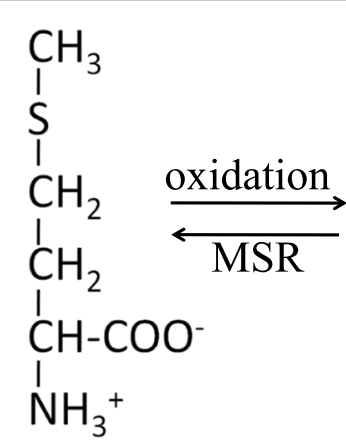

Methionine

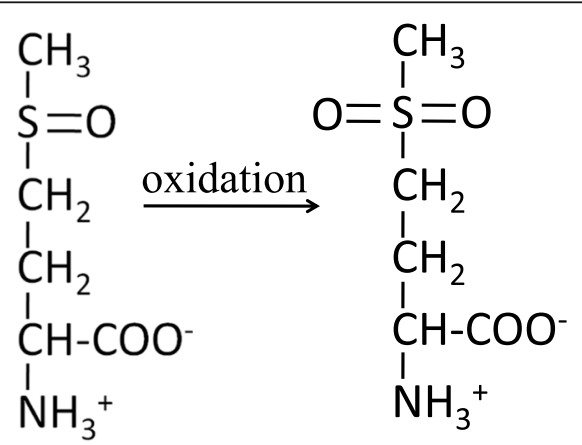

Methionine sulfoxide
Methionine sulfones

Fig. 4 Methionine sulfoxide (Met-SO) formation and repair by MSR: Under oxidative stress Met residues (free or protein bound) convert into Met$\mathrm{SO}$, further oxidation results in sulfone formation. MSR reductively repairs Met-SO to Met 
in comparison to wild-type strain and showed decreased ability to colonize in hamster lungs (Dhandayuthapani et al. 2001). In certain bacteria, MsrA and MsrB activities are carried out by a single fused protein. In Neisseria gonorrhoeae, one such protein called PilB, which was earlier supposed to have a role in pilin gene expression, was found homologous to both MsrA and MsrB of E. coli (Skaar et al. 2002). PilB is found in both secreted and cytoplasmic form, but only the secreted form of PilB was involved in the oxidative stress survival of the bacteria which was evident from the increased sensitivity of $\triangle p i l B$ null mutant and mutant overexpressing truncated form of PilB to hydrogen peroxide and superoxide compared to the wild-type strain (Skaar et al. 2002). $\triangle m s r A B$ double deletion mutant strain of Helicobacter pylori was shown to be defective in host colonization in vivo suggesting the role of MSR in pathogenesis and virulence of H. pylori (Alamuri and Maier, 2004). In Campylobacter jejuni, MsrA and MsrB proteins were found to protect against oxidative and nitrosative stress. Moreover, the $\triangle m s r A B$ double mutant strain of this bacteria showed a severe growth defect in in vitro media due to accumulation of Met-SO in proteins (Atack and Kelly, 2008). $m s r A$ and $m s r B$ genes were very essential for the protection of Enterococcus faecalis against $\mathrm{H}_{2} \mathrm{O}_{2}$ stress, and the deletion of these genes lead to attenuated virulence in mice model studies (Zhao et al. 2010). The $m s r A$ and $B$ gene deletion mutant strain of E. coli was hypersusceptible to HOCl-mediated killing (Rosen et al. 2009). Mycobacterium tuberculosis lacking both MsrA and B were shown to be hypersusceptible to nitrite and $\mathrm{HOCl}$ stress (Lee et al. 2009). The msrA mutant strain of Staphylococcus aureus were sensitive to $\mathrm{H}_{2} \mathrm{O}_{2}$ stress in vitro and phagocytic cells. Further, this mutant was less adherent to human lung epithelial cells and showed reduced survival in mouse model (Singh et al. 2015, Singh et al. 2018). In Francisella tularensis, the msrB deletion mutant was shown to be defective in growth significantly in comparison to wild type in in vitro media. Further, this strain was hypersusceptible to $\mathrm{H}_{2} \mathrm{O}_{2}$ stress and showed decreased growth in macrophages and defective in colonization in mice (Saha et al. 2017) indicating that MsrB contributes to virulence.

\section{MSRs in Salmonella}

In $S$. Typhimurium, three cytoplasmic MSRs namely, MsrA, MsrB, and MsrC, have been reported. All the three are present in cytoplasmic compartment. MsrA repairs protein-bound as well as free Met-SO and is essential for the survival of this bacterium under oxidative stress (Denkel et al. 2011; Trivedi et al. 2015). MsrB repairs protein-bound Met-SO though it is dispensable for stress survival of this bacterium (Denkel et al. 2011). The $m s r A$ and $m s r C$ gene deletion strains are

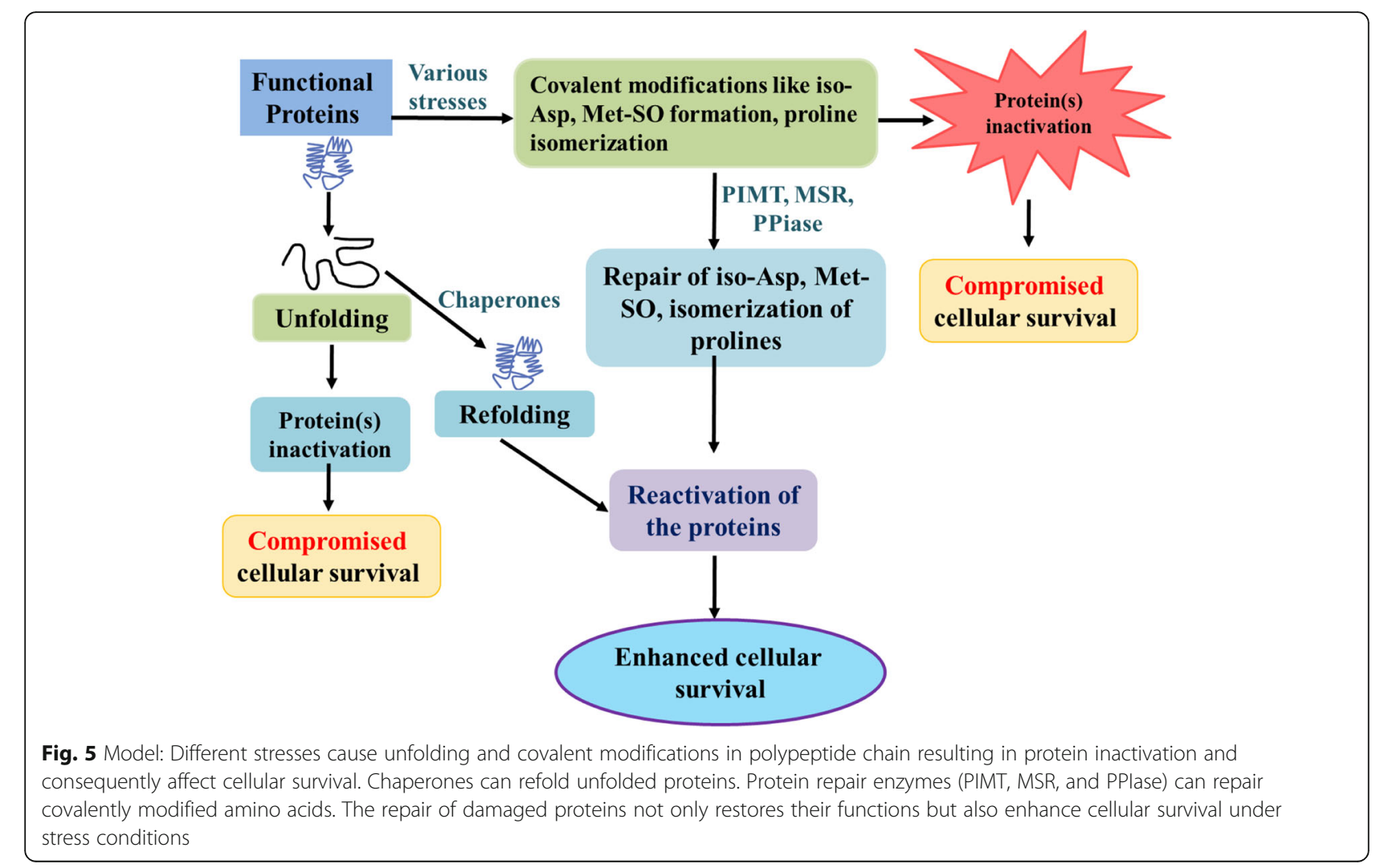


hypersensitive to phagocytic cells and showed attenuated virulence in mice and poultry (Denkel et al. 2011; Sarkhel et al. 2017). Salmonella also harbors MsrP, though the role of this protein in stress survival of most bacterial pathogens including Salmonella is not known.

\section{Conclusions}

Different stresses induce unfolding and covalent modifications in bacterial proteins that result in protein inactivation and consequently affecting cellular survival. Chaperones can refold unfolded proteins. Covalently modified amino acids are repaired by special enzymatic systems (PIMT, MSR, and PPIase). The overall goal of protein repair is to reactivate the damaged proteins without their de novo synthesis, and this process helps bacterial pathogens to overcome stress conditions, as those encountered during the infection (Fig. 5). The ways that can inhibit this process can pave the way to develop novel prophylactic and therapeutic agents against bacterial diseases.

\section{Acknowledgements}

The authors are thankful to Indian Council of Agricultural Research, India, Department of Biotechnology, Govt. of India, and the Director, ICAR- Indian Veterinary Research Institute, Izatnagar, India.

\section{Authors' contributions}

AS and MM both conceptualized the idea and wrote the review article along with the valuable inputs from all the other authors. The authors read and approved the final manuscript.

\section{Funding}

National Agricultural Sustainable Fund, Indian Council of Agricultural Research, India and Department of Biotechnology, Govt. of India.

\section{Ethics approval and consent to participate}

This research does not contain any studies with human participants or animals.

\section{Consent for publication}

Informed consent is not applicable in this work.

\section{Competing interests}

The authors declare that they have no conflict of interest.

\section{Author details \\ ${ }^{1}$ Division of Animal Biochemistry, Indian Council of Agricultural Research- Indian Veterinary Research Institute (ICAR-IVRI), Izatnagar, Bareilly 243 122, India. ${ }^{2}$ Division of Bacteriology and Mycology, Indian Council of Agricultural Research- Indian Veterinary Research Institute (ICAR-IVRI), Izatnagar, Bareilly 243 122, India.}

Received: 7 April 2020 Accepted: 28 August 2020

Published online: 17 September 2020

\section{References}

Abulimiti A, Qiu X, Chen J, Liu Y, Chang Z (2003) Reversible methionine sulfoxidation of Mycobacterium tuberculosis small heat shock protein Hsp16.3 and its possible role in scavenging oxidants. Biochem Biophys Res Commun 305:87-93

Alamuri P, Maier RJ (2004) Methionine sulphoxide reductase is an important antioxidant enzyme in the gastric pathogen Helicobacter pylori. Mol Microbiol 53:1397-1406
Alonzo F, Freitag NE (2010) Listeria monocytogenes PrsA2 is required for virulence factor secretion and bacterial viability within the host cell cytosol. Infect Immun 78:4944-4957

Atack JM, Kelly DJ (2008) Contribution of the stereospecific methionine sulphoxide reductases MsrA and MsrB to oxidative and nitrosative stress resistance in the food-borne pathogen Campylobacter jejuni. Microbiol 154: 2219-2230

Aussel L, Zhao W, Hébrard M, Guilhon AA, Viala JPM, Henri S, Chasson L, Gorvel JP, Barras F, Méresse S (2011) Salmonella detoxifying enzymes are sufficient to cope with the host oxidative burst. Mol Microbiol 80:628-640

Bailey JS, Cox NA, Craven SE, Cosby DE (2002) Serotype tracking of Salmonella through integrated broiler chicken operations. J Fd Prot 65:742-745

Behrens S, Maier R, de Cock H, Schmid FX, Gross CA (2001) The SurA periplasmic PPlase lacking its parvulin domains functions in vivo and has chaperone activity. EMBO J 20(1-2):285-294

Behrens-Kneip S (2010) The role of SurA factor in outer membrane protein transport and virulence. Int J Med Microbiol 300:421-428

Benoit SL, Maier RJ (2016) Helicobacter catalase devoid of catalytic activity protects the bacterium against oxidative stress. J Biol Chem 291:23366-23373

Bigot A, Botton E, Dubail I, Charbit A (2006) A homolog of Bacillus subtilis trigger factor in Listeria monocytogenes is involved in stress tolerance and bacterial virulence. Appl Environ Microbiol 72:6623-6631

Boschi-Muller S, Gand A, Branlant G (2008) The methionine sulfoxide reductases: catalysis and substrate specificities. Arch Biochem Biophys 474:266-273

Brandts JF, Halvorson HR, Brennan M (1975) Consideration of the possibility that the slow step in protein denaturation reactions is due to cis-trans isomerism of proline residues. Biochem 14:4953-4963

Brot N, Weissbach L, Werth J, Weissbach H (1981) Enzymatic reduction of protein-bound methionine sulfoxide. Proc Natl Acad Sci 78(4):2155-2158

Compton LA, Davis JM, Macdonald JR, Bächinger HP (1992) Structural and functional characterization of Escherichia coli peptidyl-prolyl cis-trans isomerases. Eur J Biochem 206:927-934

Cook KH, Schmid FX, Baldwin RL (1979) Role of proline isomerization in folding of ribonuclease a at low temperatures. Proc Natl Acad Sci U S A 76:6157-6161

Cron LE, Bootsma HJ, Noske N, Burghout P, Hammerschmidt S, Hermans PWM (2009) Surface-associated lipoprotein PpmA of Streptococcus pneumoniae is involved in colonization in a strain-specific manner. Microbiol 155:2401-2410

Delpino MV, Comerci DJ, Wagner MA, Eschenbrenner M, Mujer CV, Ugalde RA, Fossati CA, Baldi PC, DelVecchio VG (2009) Differential composition of culture supernatants from wild-type Brucella abortus and its isogenic virB mutants. Arch Microbiol 191:571-581

Denkel LA, Horst SA, Rouf SF, Kitowski V, Böhm OM, Rhen M, Jäger T, Bange FC (2011) Methionine sulfoxide reductases are essential for virulence of Salmonella Typhimurium. PLoS One 6(11):e26974

DeVry CG, Clarke S (1999) Polymorphic forms of the protein L-isoaspartate (Daspartate) $\mathrm{O}$ - methyltransferase involved in the repair of age-damaged proteins. J Hum Genet 44:275-288

Dhanda AS, Warren KE, Chiu RH, Guttman JA (2018) Cyclophilin a controls Salmonella internalization levels and is present at E. coli actin-rich pedestals. Anat Rec 2094:2086-2094

Dhandayuthapani S, Blaylock MW, Bebear CM, Rasmussen WG, Baseman JB (2001) Peptide methionine sulfoxide reductase (MsrA) is a virulence determinant in Mycoplasma genitalium. J Bacteriol 183:5645-5650

Dimitrijevic A, Qin Z, Aswad DW (2014) Isoaspartyl formation in creatine kinase B is associated with loss of enzymatic activity; implications for the linkage of isoaspartate accumulation and neurological dysfunction in the PIMT knockout mouse. PLoS One 9:1-8

Drew D, Sjöstrand D, Nilsson J, Urbig T, Chin C, de Gier J-W, von Heijne G (2002) Rapid topology mapping of Escherichia coli inner-membrane proteins by prediction and PhoA/GFP fusion analysis. Proc Natl Acad Sci 99:2690-2695

EFSA (European Food Safety Authority) and ECDC (European Centre for Disease Prevention and Control) (2016) The European Union summary report on trends and sources of zoonoses, zoonotic agents and food-borne outbreaks in 2015. EFSA J 14: 4634-4865.

Ezraty B, Gennaris A, Barras F, Collet J-F (2017) Oxidative stress, protein damage and repair in bacteria. Nat Rev Microbiol 15:385-396

Fang FC (1997) Perspectives series: host/pathogen interactions. Mechanisms of nitric oxide-related antimicrobial activity. J Clin Invest 99(12):2818-2825

Fang FC (2011) Antimicrobial actions of reactive oxygen species. MBio. 2(5) 
Fasseas MK, Dimou M, Katinakis P (2012) The Caenorhabditis elegans parvulin gene subfamily and their expression under cold or heat stress along with the fkb subfamily. Biochem Biophys Res Commun 423:520-525

Felmy B, Songhet P, Slack EMC, Müller AJ, Kremer M, Van Maele L, Cayet D, Heikenwalder M, Sirard JC, Hardt WD (2013) NADPH oxidase deficient mice develop colitis and bacteremia upon infection with normally avirulent, TTSS1- and TTSS-2-deficient Salmonella Typhimurium. PLoS One 8:1-10

Fields PI, Swanson R, Haidaris CG, Heffron F (1986) Mutants of Salmonella Typhimurium that cannot survive within the macrophage are avirulent. Proc Natl Acad Sci 83:5189-5193

Forster BM, Zemansky J, Portnoy DA, Marquis H (2011) Post-translocation chaperone PrsA2 regulates the maturation and secretion of Listeria monocytogenes proprotein virulence factors. J Bacteriol 193:5961-5970

Gallois A, Klein JR, Allen LAH, Jones BD, Nauseef WM (2001) Salmonella pathogenicity island 2-encoded type III secretion system mediates exclusion of NADPH oxidase assembly from the phagosomal membrane. J Immunol 166:5741-5748

Gal-Mor O, Suez J, Elhadad D, Porwollik S, Leshem E, Valinsky L, McClelland M, Schwartz E, Rahav G (2012) Molecular and cellular characterization of a Salmonella enterica serovar paratyphi a outbreak strain and the human immune response to infection. Clin Vaccine Immunol 19:146-156

Geddes K, Cruz F, Heffron (2007) Analysis of cells targeted by Salmonella type III secretion in vivo. PLoS Pathog 3: 2017-2028.

Güttler BHO, Cynis H, Seifert F, Ludwig HH, Porzel A, Schilling S (2013) A quantitative analysis of spontaneous isoaspartate formation from $\mathrm{N}$-terminal asparaginyl and aspartyl residues. Amino Acids 44(4):1205-1214

Hawkins CL, Pattison DI, Davies MJ (2003) Hypochlorite-induced oxidation of amino acids, peptides and proteins. Amino Acids 25:259-274

Hayano T, Takahashi N, Kato S, Maki N, Suzuki M (1991) Two distinct forms of peptidylprolyl-cis-trans-isomerase are expressed separately in periplasmic and cytoplasmic compartments of Escherichia coli cells. Biochem 30:3041-3048

Henard CA, Vázquez-Torres A (2011) Nitric oxide and Salmonella pathogenesis. Front Microbiol 2:1-11

Hermans PWM, Adrian PV, Albert C, Estevão S, Hoogenboezem T, Luijendijk IHT, Kamphausen T, Hammerschmidt S (2006) The streptococcal lipoprotein rotamase a $(\mathrm{S} / \mathrm{r} \mathrm{A})$ is a functional peptidyl-prolyl isomerase involved in pneumococcal colonization. J BiolChem 281:968-976

Hicks WM, Kotlajich MV, Visick JE (2005) Recovery from long-term stationary phase and stress survival in Escherichia coli require the L-isoaspartyl protein carboxyl methyltransferase at alkaline $\mathrm{pH}$. Microbiol 151:2151-2158

Hohmann EL (2001) Nontyphoidal salmonellosis. Clin Infect Dis 32(2):263-269

Horne SM, Kottom TJ, Nolan LK, Young KD (1997) Decreased intracellular survival of an fkpA mutant of Salmonella Typhimurium Copenhagen. Infect Immun 65:806-810

Humphrey T (2000) Public health aspects of Salmonella infection. In: Wray, C. and Wray, A. (eds.) Salmonella in domestic animals. CABI Publishing, U.K. pp. 245264.

Humphreys S, Rowley G, Stevenson A, Kenyon WJ, Spector MP, Roberts M (2003) Role of periplasmic peptidylprolyl isomerases in Salmonella enterica serovar Typhimurium virulence. Infect Immun 71:5386-5388

Juillan-Binard C, Picciocchi A, Andrieu JP, Dupuy J, Petit-Hartlein I, Caux-Thang C, Vivès C, Nivière V, Fieschi F (2017) A two-component NADPH oxidase (NOX)like system in bacteria is involved in the electron transfer chain to the methionine sulfoxide reductase MsrP. J Biol Chem 292:2485-2494

Justice SS, Lauer SR, Hultgren S, Hunstad DA (2006) Maturation of intracellular Escherichia coli communities requires SurA. Infect Immun 74:4793-4800

Kandror O, Goldberg AL (1997) Trigger factor is induced upon cold shock and enhances viability of Escherichia coli at low temperatures. Proc Natl AcadSci 94:4978-4981

Kenyon WJ, Humphreys S, Roberts M, Spector MP (2010) Periplasmic peptidylprolyl isomerases SurA and FkpA play an important role in the starvationstress response (SSR) of Salmonella enterica serovar Typhimurium. Antonie Van Leeuwenhoek 98(1):51-63

Kern R, Malki A, Abdallah J, Liebart JC, Dubucs C, Yu MH, Richarme G (2005) Protein isoaspartate methyltransferase is a multicopy suppressor of protein aggregation in Escherichia coli. J Bacteriol 187:1377-1383

Kim N, Weeks DL, Shin JM, Scott DR, Young MK, Sachs G (2002) Proteins released by helicobacter pylori in vitro. J Bacteriol 184:6155-6162

Kindrachuk J, Parent J, Davies GF, Dinsmore M, Attah-Poku S, Napper S (2003) Overexpression of L-Isoaspartate O-methyltransferase in Escherichia coli increases heat shock survival by a mechanism independent of methyltransferase activity. J Biol Chem 278:50880-50886

Kuhns LG, Mahawar M, Sharp JS, Benoit S, Maier RJ (2013) Role of Helicobacter pylori methionine sulfoxide reductase in urease maturation. Biochem J 450: $141-148$

Kumawat M, Pesingi PK, Agarwal RK, Goswami TK, Mahawar M (2016) Contribution of protein isoaspartate methyl transferase (PIMT) in the survival of Salmonella Typhimurium under oxidative stress and virulence. Int J Med Microbiol 306:222-230

Le Minor L, Popoff MY (1987) Designation of salmonella enterica sp. nov. as the type and only species of the genus Salmonella. Int J Syst Bacteriol 37:465468

Leach SA, Williams A, Davies AC, Wilson J, Marsh PD, Humphrey TJ (1999) Aerosol route enhances the contamination of intact eggs and muscle of experimentally infected laying hens by Salmonella Typhimurium DT104. FEMS Microbiol Lett 171:203-207

Lê-Bury G, Niedergang F (2018) Defective phagocytic properties of HIV-infected macrophages: how might they be implicated in the development of invasive Salmonella Typhimurium. Front Immunol 9:1-12

Lee WL, Gold B, Darby C, Brot N, Jiang X, De Carvalho LPS, Wellner D, St. John G, Jacobs WR, Nathan C (2009) Mycobacterium tuberculosis expresses methionine sulphoxide reductases $\mathrm{a}$ and $\mathrm{B}$ that protect from killing by nitrite and hypochlorite. Mol Microbiol 71:583-593

Li C, Clarke S (1992) A protein methyltransferase specific for altered aspartyl residues is important in Escherichia coli stationary-phase survival and heatshock resistance. Proc Natl Acad Sci 89:9885-9889

Lin W, Bonin M, Boden A, Wieduwild R, Murawala P, Wermke M, Andrade $H_{\text {, }}$ Bornhäuser M, Zhang Y (2019) Peptidyl prolyl cis/trans isomerase activity on the cell surface correlates with extracellular matrix development. Commun biol 2(1):1-11

Lin Z, Johnson LC, Weissbach H, Brot N, Lively MO, Lowther WT (2007) Free methionine-(R)-sulfoxide reductase from Escherichia coli reveals a new GAF domain function. Proc Natl Acad Sci 104(23):9597-9602

Loschi L, Brokx SJ, Hills TL, Zhang G, Bertero MG, Lovering AL, Weiner JH, Strynadka NCJ (2004) Structural and biochemical identification of a novel bacterial oxidoreductase. J Biol Chem 279:50391-50400

Luo S, Levine RL (2009) Methionine in proteins defends against oxidative stress. FASEB J 23:464-472

Mahawar M, Tran V, Sharp JS, Maier RJ (2011) Synergistic roles of Helicobacter pylori methionine sulfoxide reductase and GroEL in repairing oxidantdamaged catalase. J Biol Chem 286:19159-19169

Mandal BK, Brennand J (1988) Bacteraemia in salmonellosis: a 15 year retrospective study from regional infectious diseases unit. Br Med J 297:1242-1243

McLean S, Bowman LAH, Poole RK (2010) KatG from Salmonella Typhimurium is a peroxynitritase. FEBS Lett. 584 1628-1632.

Miller RA, Britigan BE (1997) Role of oxidants in microbial pathophysiology. Clin Microbiol Rev 10:1-18

Obi IR, Francis MS (2013) Demarcating SurA activities required for outer membrane targeting of Yersinia pseudotuberculosis adhesins. Infect Immun 81:2296-2308

Parry CM, Hien TT, Dougan G, White NJ, Farrar JJ (2002) Typhoid fever is a systemic infection with the bacterium. N Engl J Med 347:1770-1782

Pesingi PK, Kumawat M, Behera P, Dixit SK, Agarwal RK, Goswami TK, Mahawar M (2017) Protein-L-isoaspartyl methyltransferase (PIMT) is required for survival of Salmonella Typhimurium at $42{ }^{\circ} \mathrm{C}$ and contributes to the virulence in poultry. Front Microbiol 8:1-9

Popoff MY, Bockemühl J, Brenner FW (1998) Supplement 1997 (no. 41) to the Kauffmann-White scheme. Res Microbiol 149(8):601-604

Port GC, Freitag NE (2007) Identification of novel Listeria monocytogenes secreted virulence factors following mutational activation of the central virulence regulator, PrfA. Infect Immun 75:5886-5897

Purdy GE, Fisher CR, Payne SM (2007) IcsA surface presentation in Shigella flexneri requires the periplasmic chaperones DegP, Skp, and SurA. J Bacteriol 189: 5566-5573

Rasch J, Ünal CM, Klages A, Karsli Ü, Heinsohn N, Brouwer RMHJ, Richter M, Dellmann A, Steinert M (2018) Peptidyl-prolyl- cis/trans-isomerases Mip and PpiB of Legionella pneumophila contribute to surface translocation, growth at suboptimal temperature, and infection. Infect Immun 87(1)

Rosen H, Klebanoff SJ, Wang Y, Brot N, Heinecke JW, Fu X (2009) Methionine oxidation contributes to bacterial killing by the myeloperoxidase system of neutrophils. Proc Natl Acad Sci 106:18686-18691 
Saha SS, Hashino M, Suzuki J, Uda A, Watanabe K, Shimizu T, Watarai M (2017) Contribution of methionine sulfoxide reductase B (MsrB) to Francisella tularensis infection in mice. FEMS Microbiol Lett 364:1-7

Sarkhel R, Rajan P, Gupta AK, Kumawat M, Agarwal P, Shome A, Puii L, Mahawar M (2017) Methionine sulfoxide reductase a of Salmonella Typhimurium interacts with several proteins and abets in its colonization in the chicken. Biochem Biophys Acta - Gen Subj 1861:3238-3245

Schmalstig AA, Benoit SL, Misra SK, Sharp JS, Maier RJ (2018) Non catalytic antioxidant role for Helicobacter pylori urease. J Bacteriol 200(17):e00124e00118

Schmid FX, Mayr LM, Mucke M, Schonbrunner ER (1993) Prolyl isomerases: role in protein folding. Adv Protein Chem 44:25-66

Shimizu T, Matsuoka Y, Shirasawa T (2005) Biological significance of isoaspartate and its repair system. Biol Pharm Bull 28:1590-1596

Singh V, Singh K, Baum K (2018) The role of methionine sulfoxide reductases in oxidative stress tolerance and virulence of Staphylococcus aureus and other bacteria. Antioxidants 7:128

Singh VK, Vaish M, Johansson TR, Baum KR, Ring RP, Singh S, Shukla SK, Moskovitz J (2015) Significance of four methionine sulfoxide reductases in Staphylococcus aureus. PLoS One 10:1-20

Skaar EP, Tobiason DM, Quick J, Judd RC, Weissbach H, Etienne F, Brot N, Seifert HS (2002) The outer membrane localization of the Neisseria gonorrhoeae MsrA/B is involved in survival against reactive oxygen species. Proc Natl Acad Sci 99:10108-10113

Slauch JM (2011) How does the oxidative burst of macrophages kill bacteria? Still an open question. Mol Microbiol 80:580-583

Söderberg MA, Cianciotto NP (2008) A Legionella pneumophila peptidyl-prolyl cistrans isomerase present in culture supernatants is necessary for optimal growth at low temperatures. Appl Environ Microbiol 74:1634-1638

Sydenham M, Douce G, Bowe F, Ahmed S, Chatfield S, Dougan G (2000) Salmonella enterica serovar Typhimurium surA mutants are attenuated and effective live oral vaccines. Infect Immun 68:1109-1115

Trivedi RN, Agarwal P, Kumawat M, Pesingi PK, Gupta VK, Goswami TK, Mahawar M (2015) Methionine sulfoxide reductase a (MsrA) contributes to Salmonella Typhimurium survival against oxidative attack of neutrophils. Immunobiol 220:1322-1327

Ünal CM, Berges M, Smit N, Schiene-Fischer C, Priebe C, Strowig T, Jahn D, Steinert M (2018) PrsA2 (CD630_35000) of Clostridioides difficile is an active parvulin-type PPlase and a virulence modulator. Front Microbiol 9:2913

Unal CM, Steinert M (2014) Microbial peptidyl-prolyl cis/trans isomerases (PPlases): virulence factors and potential alternative drug targets. Microbiol Mol Biol Rev 78:544-571

Vazquez-Torres A, Xu Y, Jones-Carson J, Holden DW, Lucia SM, Dinauer MC, Mastroeni P, Fang FC (2000) Salmonella pathogenicity island 2-dependent evasion of the phagocyte NADPH oxidase. Sci 287:1655-1658

Velge P, Cloeckaert A, Barrow P (2005) Emergence of Salmonella epidemics: the problems related to Salmonella enterica serotype Enteritidis and multiple antibiotic resistance in other major serotypes. Vet Res 36:267-288

Verma P, Singh A, Kaur H, Majee M (2010) Protein l-isoaspartyl methyltransferase1 (CaPIMT1) from chickpea mitigates oxidative stress-induced growth inhibition of Escherichia coli. Planta 231:329-336

Vigneswara V, Lowenson JD, Powell CD, Thakur M, Bailey K, Clarke S, Ray DE, Carter WG (2006) Proteomic identification of novel substrates of a protein isoaspartyl methyltransferase repair enzyme. J Biol Chem 281:32619-32629

Visick JE, Cai HUI, Clarke S (1998) The L-isoaspartyl protein repair methyltransferase enhances survival of aging Escherichia coli subjected to secondary environmental stresses. J Bacteriol 180:2623-2629

WHO (2015) WHO estimates of the global burden of foodborne diseases. Foodborne Dis Burden Epidemiol Reference group:2007

Wu T, Zhao Z, Zhang L, Ma H, Lu K, Ren W, Liu Z, Chang H, Bei W, Qiu Y, Chen H (2011) Trigger factor of Streptococcus suis is involved in stress tolerance and virulence. Microb Pathog 51(1-2):69-76

Zhang XH, Weissbach H (2008) Origin and evolution of the protein-repairing enzymes methionine sulphoxide reductases. Biol Rev 83(3):249-257

Zhao C, Hartke A, La Sorda M, Posteraro B, Laplace J, Auffray Y, Sanguinetti M (2010) Role of methionine sulfoxide reductases a and B of Enterococcus faecalis in oxidative stress and virulence. Infect Immun 78:3889-3897

\section{Publisher's Note}

Springer Nature remains neutral with regard to jurisdictional claims in published maps and institutional affiliations.

\section{Ready to submit your research? Choose BMC and benefit from:}

- fast, convenient online submission

- thorough peer review by experienced researchers in your field

- rapid publication on acceptance

- support for research data, including large and complex data types

- gold Open Access which fosters wider collaboration and increased citations

- maximum visibility for your research: over $100 \mathrm{M}$ website views per year

At BMC, research is always in progress.

Learn more biomedcentral.com/submissions 